\title{
The Relationship between Hormone Replacement Therapy and Periodontal Disease in Postmenopausal Women
}

\author{
Eunsuk Ahn and Yunhee Lee ${ }^{\dagger}$ \\ Department of Dental Hygiene, Kyungbok University, Pocheon 11138, Korea
}

The purpose of this study was to investigate the relationship between hormone replacement therapy (HRT) and periodontal disease in postmenopausal women using data from the 4th and 5th Korea National Health and Nutrition Examination Survey. A total of 5,482 postmenopausal women aged $45 \sim 75$ years were included as study subjects in the final analysis. The HRT group comprised 1,035 postmenopausal women who had received HRT for at least one month, and the non-HRT group comprised 4,447 postmenopausal women who did not receive HRT. The chi-square test was used to confirm the bivariate relationship between the variables. Multinomial logistic regression analysis was used to adjust for covariance (age, education, family income, body mass index, age of menopause, alcohol, smoking, dental visit <1 per year, use of oral care products, and frequency of tooth brushing per day). After adjusting for all covariates, HRT was found to be associated with periodontal disease. In particular, the relationship between HRT and periodontal disease was more evident in older women and women younger than 45 years of menopausal age. The relationship between HRT and periodontal disease was stronger in women who brushed their teeth less than 3 times per day, women without regular oral examination, and women who did not use oral hygiene products. The results of this study confirmed the importance of actively considering hormone therapy when determining policy recommendations for postmenopausal women. Especially, health programs such as HRT, regular dental examination, and oral care are needed for older women who have undergone premature menopause.

Key Words: Hormone replacement therapy, Menopause, Periodontal diseases

\section{Introduction}

The World Health Organization (WHO) has defined natural menopause as 12 months of continued amenorrhea without clear reasons such as pregnancy or breastfeeding ${ }^{11}$. Korean women's life expectancy in 2015 was 85.2 years, 6.2 longer than men's life expectancy of $79.0^{2}$. The average menopausal age is 49.7 , and women spend 35.5 years, more than a third of their life, in a postmenopausal state ${ }^{3)}$. According to Statistic Korea, postmenopausal women aged 50 years or older were estimated to account for $34.8 \%$ of all women in Korea in $2015^{4)}$, and it is estimated that $43.2 \%$ of the women will be postmenopausal in $2030^{5}$. While menopause is a natural phenomenon that occurs due to aging, the risk of osteoporotic, cardiovascular, and other diseases increases for women after menopause $^{6}$. In addition, menopause is known to affect the oral environment, and changes in sex hormones such as estrogen, progesterone, and testosterone have an effect on the release of proinflammatory cytokines, which are involved in bone resorption, and can lead to an increase in the inflammation of periodontal tissues ${ }^{7}$. The oral mucosa includes estrogen receptors, and it is known that changes in hormone levels have a direct effect on the oral environment $^{8}$. According to previous studies, women experience periodontal disease related to sex hormones over the course of decades in their life due to puberty, menstruation, pregnancy, and menopause ${ }^{9,10)}$. 
The need for hormone replacement therapy (HRT) was raised to alleviate climacteric symptoms related to menopause and to improve women's quality of life ${ }^{11)}$. HRT decreases the loss of bone mass and plays an important role in preventing osteoporosis after menopause ${ }^{12)}$. Previous studies showed that HRT had a positive effect on preserving alveolar bone density and the number of teeth $^{13,14)}$. Similarly, when estrogen was administered to mice, the hormone was effective in preventing the loss of alveolar bone, which is caused by estrogen deficiency ${ }^{15)}$. Meanwhile, there are conflicting reports on the degree to which HRT affects the periodontal tissue and its effect on the depth of periodontal pockets ${ }^{16,17)}$.

These previous research findings present an association between HRT and periodontal disease in women after menopause. However, the findings are not consistent, and few studies have used representative data to analyze the association between HRT and periodontal disease. In this regard, this study aims to identify the relationship between HRT and the risk of periodontal disease in Korean postmenopausal women, as well as provide basic data to establish policies for preventing periodontal disease in postmenopausal women.

\section{Materials and Methods}

\section{Subjects}

First, it was necessary to define natural menopause in order to limit the subjects to postmenopausal women. Natural menopause is defined as 12 months of continued amenorrhea without clear reasons such as pregnancy or breastfeeding ${ }^{1)}$. Therefore, this study limited its subjects to women who were aged 45 to 75 years, based on the postmenopausal period defined by the Korean Society of Menopause, and who responded that they had natural menopause. This study excluded those who responded that they had artificial menopause due to a hysterectomy, those who were diagnosed by a doctor with diabetes, which is closely correlated to periodontal disease, and those who did not provide 1 or more responses in a questionnaire. Questions on the age at which they began HRT and the HRT period were removed in the 5th Korea National Health and Nutrition Examination Survey (KNHANES)
(2010 2012), so results for those questions were only included from the 4th KNHANES (2007 2009). The total number of participants in the 4 th and 5th KNHANES (those in 2011 were excluded due to an error in measurements among periodontal disease survey researchers) was 41,887 , and among them, 5,482 were included as the final subjects. The subjects were 5,482 postmenopausal women; 1,035 who responded that they had taken female hormones for at least more than a month and 4,447 who said they had not. This study obtained and used approval for the exemption of a bioethics review from the Institution Bioethics Committee of Hanyang University (HYI-16-195).

\section{Variables used for analysis}

This study re-categorized the community periodontal index of treatment needs (CPITN), which is indicated on a scale of 0 to 4 , into healthy periodontal tissue (0), gingivitis $(1 \sim 2)$, and periodontitis $(3 \sim 4)$, and used these factors as dependent variables. The independent variables included previous administration of HRT $(\mathrm{HRT}+/ \mathrm{HRT}-)$, body mass index (BMI) (normal/obese), and age of menopause (younger than 45 years/45 50 years/51 years or older). In addition, this study also included general characteristics such as age $(45 \sim 54$ years/55 $\sim 64$ years/65 74 years), education (elementary and below/middle/high and above), and family income (low/middle low/middle upper/ upper); lifestyle habits such as alcohol (no/past/drinking) and smoking (no/yes); and the status of oral care such as dental visit in the per year (yes/no), use of oral care products (yes/no), and frequency of tooth brushing per day (less than 3 times/3 times or more).

\section{Analysis method}

Considering that the KNHANES was a survey using a composite sampling design, this study generated a plan file before analysis and analyzed the composite sampling design. This study used the estimated variance stratum as the stratification variable, the surveyed district as the cluster variable, and a sampling frame as the weight; to adjust for coverage error arising from a gap between households and the population at the time of a survey and non-response error caused by non-participation in the survey, this study used correlation analysis weights and 
calculated new weights. When cases were deleted, composite sampling information included in the deleted data could be missing and create a biased estimator of the standard deviation; this study generated the focus group and other groups and then analyzed them. All analyses were performed using IBM SPSS Statistics ver. 22.0 (IBM Co., Armonk, NY, USA). To identify the subjects' basic information, this study used a frequency analysis and descriptive statistics. To identify HRT differences depending on demographic characteristics, lifestyle habits, and oral care, the chi-squared test was used. In addition, multinomial logistic regression analysis was conducted to identify the association between HRT and the risk of periodontal disease, and the adjusted odds ratio (adjusted OR) and $95 \%$ confidence interval (CI) were calculated. p-values $<0.05$ were considered to indicate statistical significance.

\section{Results}

\section{General characteristics of the subjects}

Among all 5,482 subjects, $81.2 \%$ were in the non-HRT group of women who said they had never had HRT, and $18.8 \%$ were in in the HRT group of women who said they had; the percentage of the non-HRT group was higher. For age groups, $42.0 \%$ were " $55 \sim 64$ years", $29.7 \%$, " $45 \sim 54$ years", and $28.3 \%$, “65 74 years". For education, "elementary and below" accounted for more than half of the subjects $54.5 \%$. For family income, "middle low" accounted for $28.6 \%$ and "low" accounted for $27.7 \%$. For the age of menopause, " $45 \sim 50$ years" accounted for the highest percentage $45.7 \%$. For drinking, "past" accounted for the highest percentage $41.9 \%$, and for smoking, "no" accounted for the highest percentage $91.6 \%$. For frequency of tooth brushing per day, "less than 3 times" accounted for $62.4 \%$, and " 3 times or more" for $37.6 \%$ (Table 1).

\section{HRT status based on general characteristics,} lifestyle habits, and oral care

Depending on HRT, there were significant differences in age, education, family income, BMI, age of menopause, drinking, dental visit in the past 1 year, and use of oral care products $(p<0.05)$. In both the HRT and non-HRT groups, those aged "55 64 years" accounted for the highest percentage, but there were differences in other age groups; $32.1 \%$ were aged " $45 \sim 54$ years" years in the HRT group, whereas $30.6 \%$ were aged "65 74 years" years in the non-HRT group. For family income, the HRT group had a relatively higher family income level than the non-HRT group (Table 2).

\section{Variables that had an effect on periodontal status}

Table 3 shows the results of a multinomial logistic regression analysis conducted to identify which variables including HRT, general characteristics, lifestyle habits, and oral care, had an effect on periodontal status. When adjusting for all other variables, the non-HRT group had

Table 1. General Characteristics of the Study Population $(n=5,482)$

\begin{tabular}{|c|c|c|}
\hline Characteristic & Group & $\mathrm{n}$ (weighted \%) \\
\hline \multirow[t]{2}{*}{ HRT status } & HRT - & $4,447(81.2)$ \\
\hline & HRT + & $1,035(18.8)$ \\
\hline \multirow[t]{3}{*}{ Age (y) } & $45 \sim 54$ & $1,256(29.7)$ \\
\hline & $55 \sim 64$ & $2,241(42.0)$ \\
\hline & $65 \sim 74$ & $1,985(28.3)$ \\
\hline \multirow[t]{3}{*}{ Education } & Elementary and below & $3,245(54.5)$ \\
\hline & Middle & $911(18.5)$ \\
\hline & High and above & $1,326(27.0)$ \\
\hline \multirow[t]{4}{*}{ Family income $^{a}$} & Low & $1,757(27.7)$ \\
\hline & Middle low & $1,517(28.6)$ \\
\hline & Middle upper & $1,118(21.8)$ \\
\hline & Upper & $1,090(21.9)$ \\
\hline \multirow[t]{2}{*}{ Body mass index ${ }^{b}$} & Normal & $3,317(60.9)$ \\
\hline & Obese & $2,165(39.1)$ \\
\hline \multirow[t]{3}{*}{ Age of menopause (y) } & $<45$ & $800(14.1)$ \\
\hline & $45 \sim 50$ & $1,863(45.7)$ \\
\hline & $\geq 51$ & $2,819(40.2)$ \\
\hline \multirow[t]{3}{*}{ Alcohol } & No & $1,725(29.3)$ \\
\hline & Past & 2,317 (41.9) \\
\hline & Drinking & $1,440(28.7)$ \\
\hline \multirow[t]{2}{*}{ Smoking } & No & $5,090(91.6)$ \\
\hline & Yes & $392(8.4)$ \\
\hline \multirow[t]{2}{*}{ Dental visit $<1$ year } & No & $4,272(77.5)$ \\
\hline & Yes & $1,210(22.5)$ \\
\hline \multirow{2}{*}{$\begin{array}{l}\text { Use of oral care } \\
\text { products }\end{array}$} & No & $3,964(71.0)$ \\
\hline & Yes & $1,518(29.0)$ \\
\hline \multirow{2}{*}{$\begin{array}{c}\text { Frequency of tooth } \\
\text { brushing per day }\end{array}$} & $<3$ times & $3,460(62.4)$ \\
\hline & $\geq 3$ times & $2,022(37.6)$ \\
\hline
\end{tabular}

HRT: hormone replacement therapy.

${ }^{a}$ Income quartile. ${ }^{b}$ Asia-Pacific Standard: normal, less than 25 $\mathrm{kg} / \mathrm{m}^{2}$; obese, more than $25 \mathrm{~kg} / \mathrm{m}^{2}$. 
Table 2. HRT Status Based on General Characteristics $(n=5,482)$

\begin{tabular}{|c|c|c|c|c|}
\hline Characteristic & Group & $\begin{array}{c}\text { HRT - } \\
\mathrm{n}=4,447(81.2 \%)\end{array}$ & $\begin{array}{c}\text { HRT }+ \\
\mathrm{n}=1,035(18.8 \%)\end{array}$ & p-value \\
\hline \multirow[t]{3}{*}{ Age (y) } & $45 \sim 54$ & $990(29.1)$ & $266(32.1)$ & \multirow{3}{*}{$<0.001 *$} \\
\hline & $55 \sim 64$ & $1,726(40.3)$ & $515(49.6)$ & \\
\hline & $65 \sim 74$ & $1,731(30.6)$ & $254(18.4)$ & \\
\hline \multirow[t]{3}{*}{ Education } & Elementary and below & $2,785(57.1)$ & $460(43.1)$ & \multirow{3}{*}{$<0.001 *$} \\
\hline & Middle & $693(17.6)$ & $218(22.1)$ & \\
\hline & High and above & $969(25.2)$ & $357(34.8)$ & \\
\hline \multirow[t]{4}{*}{ Family income $^{a}$} & Low & $1,543(29.7)$ & $214(19.1)$ & \multirow{4}{*}{$<0.001 *$} \\
\hline & Middle low & $1,228(28.2)$ & $289(30.3)$ & \\
\hline & Middle upper & $867(21.4)$ & $251(23.7)$ & \\
\hline & Upper & 809 (20.7) & $281(27.0)$ & \\
\hline \multirow[t]{2}{*}{ Body mass index ${ }^{b}$} & Normal & $2,662(59.7)$ & $655(65.9)$ & \multirow{2}{*}{$0.003 *$} \\
\hline & Obese & $1,785(40.3)$ & $380(34.1)$ & \\
\hline \multirow[t]{3}{*}{ Age of menopause (y) } & $<45$ & $637(13.7)$ & $163(16.1)$ & \multirow{3}{*}{$0.002 *$} \\
\hline & $45 \sim 50$ & $1,473(33.6)$ & $390(38.2)$ & \\
\hline & $\geq 51$ & $2,337(52.8)$ & $482(45.6)$ & \\
\hline \multirow[t]{3}{*}{ Alcohol } & No & $1,459(30.4)$ & $266(24.8)$ & \multirow{3}{*}{$0.004 *$} \\
\hline & Past & $1,868(41.8)$ & $449(42.3)$ & \\
\hline & Drinking & $1,120(27.8)$ & $320(32.8)$ & \\
\hline \multirow[t]{2}{*}{ Smoking } & No & $4,127(91.6)$ & 963 (91.6) & \multirow{2}{*}{0.963} \\
\hline & Yes & $320(8.4)$ & $72(8.4)$ & \\
\hline \multirow[t]{2}{*}{ Dental visit $<1$ year } & No & $3,531(79.0)$ & $741(71.1)$ & \multirow{2}{*}{$<0.001 *$} \\
\hline & Yes & $916(21.0)$ & $294(28.9)$ & \\
\hline \multirow[t]{2}{*}{ Use of oral care products } & No & $3,337(73.0)$ & $627(62.3)$ & \multirow{2}{*}{$<0.001 *$} \\
\hline & Yes & $1,110(27.0)$ & $408(37.7)$ & \\
\hline \multirow{2}{*}{ Frequency of tooth brushing per day } & $<3$ times & $2,852(63.0)$ & $608(60.0)$ & \multirow{2}{*}{0.149} \\
\hline & $\geq 3$ times & $1,595(37.0)$ & $427(40.0)$ & \\
\hline
\end{tabular}

Values are presented as $\mathrm{n}$ (weighted \%).

HRT: hormone replacement therapy.

${ }^{*} \mathrm{p}<0.05$.

${ }^{\mathrm{a}}$ Income quartile. ${ }^{\mathrm{b}}$ Asia-Pacific Standard: normal, less than $25 \mathrm{~kg} / \mathrm{m}^{2}$; obese, more than $25 \mathrm{~kg} / \mathrm{m}^{2}$.

an adjusted OR of 1.27 (95\% CI, $1.01 \sim 1.58)$ to progress into gingivitis compared to the HRT group, and an adjusted OR of 1.40 (95\% CI, $1.10 \sim 1.76)$ to progress into periodontitis. Those aged " $45 \sim 54$ years" had an adjusted OR of 1.40 (95\% CI, $1.05 \sim 1.87)$ to progress into gingivitis compared to those aged " $65 \sim 74$ years". Those with an education level of "elementary and below" had an adjusted OR of 1.41 (95\% CI, $1.07 \sim 1.85$ ) to progress into gingivitis compared to those with an education level "high and above", and an adjusted OR of 1.46 (95\% CI, 1.11 1.93) to progress into periodontitis. Those who were "obese" had an adjusted OR of 1.28 (95\% CI, $1.05 \sim 1.57$ ) to progress into periodontitis compared to those who were "normal". For smoking, those who responded "yes" had an adjusted OR of 1.51 (95\% CI, $1.01 \sim 2.27)$ to progress into periodontitis. For dental visit in the past 1 year, those who responded "no" had an adjusted OR of 1.59 (95\% CI, $1.26 \sim 1.99)$ to progress into gingivitis. For use of oral care products, those who responded "no" had an adjusted OR of 1.61 (95\% CI, $1.29 \sim 2.01$ ) to progress into periodontitis. For frequency of tooth brushing per day, those who brushed "less than 3 times" a day had an adjusted OR of 1.22 (95\% CI, 1.00 1.49) to progress into gingivitis, and an adjusted OR of $1.30(95 \% \mathrm{CI}, 1.08 \sim 1.58)$ to progress into periodontitis. 
Table 3. Periodontal Status Based on HRT, General Characteristics, Lifestyle Habits, and Oral Care $(n=5,482)$

\begin{tabular}{|c|c|c|c|}
\hline \multirow{2}{*}{ Characteristic } & \multirow{2}{*}{ Group } & CPITN $1 \sim 2$ & CPITN $3 \sim 4$ \\
\hline & & $\mathrm{aOR}(95 \% \mathrm{CI})$ & $\mathrm{aOR}(95 \% \mathrm{CI})$ \\
\hline \multirow[t]{2}{*}{ HRT } & HRT - & $1.27(1.01 \sim 1.58)^{*}$ & $1.40(1.10 \sim 1.76)^{*}$ \\
\hline & HRT + & 1.00 & 1.00 \\
\hline \multirow[t]{3}{*}{ Age (y) } & $45 \sim 54$ & $1.40(1.05 \sim 1.87)^{*}$ & $0.99(0.75 \sim 1.34)$ \\
\hline & $55 \sim 64$ & $1.10(0.87 \sim 1.39)$ & $1.13(0.90 \sim 1.42)$ \\
\hline & $65 \sim 74$ & 1.00 & 1.00 \\
\hline \multirow[t]{3}{*}{ Education } & Elementary and below & $1.41(1.07 \sim 1.85)^{*}$ & $1.46(1.11 \sim 1.93)^{*}$ \\
\hline & Middle & $1.13(0.84 \sim 1.51)$ & $0.99(0.73 \sim 1.37)$ \\
\hline & High and above & 1.00 & 1.00 \\
\hline \multirow[t]{4}{*}{ Family income $^{\mathrm{a}}$} & Low & $0.90(0.67 \sim 1.21)$ & $1.20(0.88 \sim 1.64)$ \\
\hline & Middle low & $0.86(0.64 \sim 1.16)$ & $1.23(0.91 \sim 1.65)$ \\
\hline & Middle upper & $0.99(0.74 \sim 1.33)$ & $1.27(0.96 \sim 1.70)$ \\
\hline & Upper & 1.00 & 1.00 \\
\hline \multirow[t]{2}{*}{ Body mass index ${ }^{b}$} & Obese & $1.07(0.87 \sim 1.32)$ & $1.28(1.05 \sim 1.57)^{*}$ \\
\hline & Normal & 1.00 & 1.00 \\
\hline \multirow{3}{*}{ Age of menopause (y) } & $<45$ & $0.89(0.69 \sim 1.14)$ & $1.03(0.77 \sim 1.38)$ \\
\hline & $45 \sim 50$ & $1.05(0.85 \sim 1.30)$ & $1.15(0.92 \sim 1.43)$ \\
\hline & $\geq 51$ & 1.00 & 1.00 \\
\hline \multirow[t]{3}{*}{ Alcohol } & No & $0.91(0.71 \sim 1.17)$ & $0.90(0.70 \sim 1.16)$ \\
\hline & Past & $0.95(0.76 \sim 1.19)$ & $0.93(0.74 \sim 1.17)$ \\
\hline & Drinking & 1.00 & 1.00 \\
\hline \multirow[t]{2}{*}{ Smoking } & No & 1.00 & 1.00 \\
\hline & Yes & $1.04(0.71 \sim 1.52)$ & $1.51(1.01 \sim 2.27)^{*}$ \\
\hline \multirow[t]{2}{*}{ Dental visit $<1$ year } & No & $1.59(1.26 \sim 1.99)^{*}$ & $1.12(0.87 \sim 1.44)$ \\
\hline & Yes & 1.00 & 1.00 \\
\hline \multirow[t]{2}{*}{ Use of oral care products } & No & $1.22(0.98 \sim 1.51)$ & $1.61(1.29 \sim 2.01)^{*}$ \\
\hline & Yes & 1.00 & 1.00 \\
\hline \multirow[t]{2}{*}{ Frequency of tooth brushing per day } & $<3$ times & $1.22(1.00 \sim 1.49)^{*}$ & $1.30(1.08 \sim 1.58)^{*}$ \\
\hline & $\geq 3$ times & 1.00 & 1.00 \\
\hline
\end{tabular}

p-values were analyzed by multinomial logistic regression.

HRT: hormone replacement therapy, CPITN: community periodontal index of treatment needs, CPITN 1 2: gingivitis, CPITN $3 \sim 4$ : periodontitis, aOR: adjusted odds ratio, $\mathrm{CI}$ : confidence interval. ${ }^{*} \mathrm{p}<0.05$.

${ }^{\mathrm{a}}$ Income quartile. ${ }^{\mathrm{b}}$ Asia-Pacific Standard: normal, less than $25 \mathrm{~kg} / \mathrm{m}^{2}$; obese, more than $25 \mathrm{~kg} / \mathrm{m}^{2}$.

\section{HRT's effect on periodontal status depending on age, age of menopause, and oral care}

Table 4 shows the results of a multinomial logistic regression analysis conducted to identify HRT's effect on periodontal status depending on age, age of menopause, and oral care after stratifying each variable and applying it to each model. When adjusting for other factors, those aged "65 74 years" in the non-HRT group had an adjusted OR of 2.36 (95\% CI, $1.52 \sim 3.68$ ) to progress into gingivitis compared to those in the HRT group, and an adjusted OR of 2.63 (95\% CI, 1.69 4.07) to progress into periodontitis. For age of menopause, those who had meno- pause at "age 45 years or less" in the non-HRT group had an adjusted OR of 1.49 (95\% CI, 1.08 2.06) to progress into gingivitis compared to those in the HRT group, and an adjusted OR of 1.58 (95\% CI, 1.14 2.19) to progress into periodontitis.

For dental visit in the past 1 year, those who responded "no" in the non-HRT group had an adjusted OR of 1.38 (95\% CI, 1.06 1.80) to progress into gingivitis compared to those in the HRT group, and an adjusted OR of 1.60 (95\% CI, 1.21 2.11) to progress into periodontitis. For use of oral care products, those who responded "no" in the non-HRT group had an adjusted OR of 1.46 (95\% CI, 1.03 
Table 4. The Relationship between HRT and CPITN by Age, Age of Menopause, and Oral Care $(n=5,482)$

\begin{tabular}{|c|c|c|c|}
\hline \multirow{3}{*}{ Stratum } & \multicolumn{3}{|c|}{ CPITN } \\
\hline & 0 & $1 \sim 2$ & $3 \sim 4$ \\
\hline & $\mathrm{aOR}$ & $\mathrm{aOR}(95 \% \mathrm{CI})$ & $\mathrm{aOR}(95 \% \mathrm{CI})$ \\
\hline \multicolumn{4}{|l|}{ Age $(y)^{a}$} \\
\hline $45 \sim 54$ & 1.00 & $0.86(0.57 \sim 1.30)$ & $1.03(0.65 \sim 1.64)$ \\
\hline $55 \sim 64$ & 1.00 & $1.23(0.88 \sim 1.71)$ & $1.25(0.89 \sim 1.77)$ \\
\hline $65 \sim 74$ & 1.00 & $2.36(1.52 \sim 3.68) * * *$ & $2.63(1.69 \sim 4.07)^{* * *}$ \\
\hline \multicolumn{4}{|c|}{ Age of menopause $(y)^{b}$} \\
\hline$<45$ & 1.00 & $1.49(1.08 \sim 2.06)^{* *}$ & $1.58(1.14 \sim 2.19)^{* *}$ \\
\hline $45 \sim 50$ & 1.00 & $1.05(0.72 \sim 1.52)$ & $1.11(0.74 \sim 1.65)$ \\
\hline$\geq 51$ & 1.00 & $0.99(0.58 \sim 1.69)$ & $1.61(0.90 \sim 2.87)$ \\
\hline \multicolumn{4}{|c|}{ Dental visit $<1$ year $^{\mathrm{c}}$} \\
\hline No & 1.00 & $1.38(1.06 \sim 1.80)^{*}$ & $1.60(1.21 \sim 2.11)^{* *}$ \\
\hline Yes & 1.00 & $1.11(0.74 \sim 1.66)$ & $0.97(0.65 \sim 1.44)$ \\
\hline \multicolumn{4}{|c|}{ Use of oral care products ${ }^{\mathrm{d}}$} \\
\hline No & 1.00 & $1.38(0.99 \sim 1.92)$ & $1.46(1.03 \sim 2.08)^{*}$ \\
\hline Yes & 1.00 & $1.20(0.89 \sim 1.63)$ & $1.32(0.97 \sim 1.80)$ \\
\hline \multicolumn{4}{|c|}{ Frequency of tooth brushing per day ${ }^{\mathrm{e}}$} \\
\hline$<3$ & 1.00 & $1.27(0.93 \sim 1.74)$ & $1.40(1.02 \sim 1.91)^{*}$ \\
\hline$\geq 3$ & 1.00 & $1.26(0.89 \sim 1.77)$ & $1.35(0.94 \sim 1.95)$ \\
\hline
\end{tabular}

p-values were analyzed by multinomial logistic regression.

CPITN: community periodontal index of treatment needs, CPITN 1 2: gingivitis, CPITN 3 4: periodontitis, aOR: adjusted odds ratio, $\mathrm{CI}$ : confidence interval.

${ }^{*} \mathrm{p}<0.05,{ }^{* *} \mathrm{p}<0.01,{ }^{* * *} \mathrm{p}<0.001$

adjusted for education, family income, body mass index (BMI), age of menopause, alcohol, smoking, dental visit $<1$ per year, use of oral care products, and frequency of tooth brushing per day.

${ }^{\mathrm{b}}$ Adjusted for age, education, family income, BMI, alcohol, smoking, dental visit $<1$ per year, use of oral care products, and frequency of tooth brushing per day.

'Adjusted for age, education, family income, BMI, age of menopause, alcohol, smoking, use of oral care products, and frequency of tooth brushing per day.

${ }^{\mathrm{d}}$ Adjusted for age, education, family income, BMI, age of menopause, alcohol, smoking, dental visit $<1$ per year, and frequency of tooth brushing per day.

${ }^{\mathrm{e}}$ Adjusted for age, education, family income, BMI, age of menopause, alcohol, smoking, dental visit $<1$ per year, and use of oral care products.

2.08) to progress into periodontitis compared to those in the HRT group. For frequency of tooth brushing per day, those who brushed their teeth "less than 3" times in the non-HRT group had an adjusted OR of 1.40 (95\% CI, 1.02 1.91) to progress into periodontitis compared to those in the HRT group.

\section{Discussion}

After menopause, a woman's body experiences a drastic reduction occurs in bone mass due to estrogen deficiency ${ }^{18,19)}$. HRT is widely perceived as a way to prevent disease and increase lifespan ${ }^{20}$, and since periodontal disease is affected by the alveolar bone status, many studies are being conducted to prove a relationship between HRT and periodontal disease ${ }^{16,21)}$. In this regard, under the assumption that HRT, which is closely correlated to the bone mass of postmenopausal women, would be also closely associated to periodontal status, this study used the 4th and 5th KNHANES data. By analyzing the relationship between HRT and the risk of periodontal disease in Korean postmenopausal women, this study intended to provide basic data that can be used when establishing oral health policies for postmenopausal women in accordance with their life cycle.

When adjusting the potential variables for various periodontal diseases, an association between HRT and periodontal diseases was found. This study analyzed postmenopausal women aged $45 \sim 74$ years and revealed that the non-HRT group had a higher possibility of progressing into gingivitis or periodontitis, which supports previous research findings. In a patient-control group study by Haas et al. ${ }^{13)}$ on Brazilian women aged $40 \sim 69$ years, the postmenopausal non-HRT group was 2.10 times more likely to have periodontal disease than women before menopause, and the postmenopausal HRT group was 1.11 times more likely to have periodontal disease than women before menopause. In a similar context, HRT can be a method to reduce the risk of deteriorating periodontal status. However, in their study on 91 postmenopausal women aged 50 62 years, Pizzo et al. ${ }^{16)}$ reported that the non-HRT group had a higher level of dental plaque, but no difference in depth of periodontal pockets, compared to the HRT group. In addition, López-Marcos et al. ${ }^{22)}$ performed a patient-control group study on 210 postmenopausal women in Spain aged 40 58 years and found that the depth of periodontal pockets decreased in the estrogen patch group, but estrogen had no correlation with gingival recession; therefore, they reported that HRT should be considered in the oral care 
treatment of postmenopausal women. These conflicting research findings are attributable to the fact that the subjects' age and continued HRT period were different, and clinical assessment tools to determine periodontal status were also different. More importantly, the different results in Singh et al.'s study ${ }^{23)}$, even if the subjects' ages were similar, could be attributed to different categorization based on the age of menopause. Compared with previous studies that did not consider these variables, the present study is significant because it used the CPITN, an objective tool to assess periodontal tissue status, which was categorized into healthy periodontal tissue, gingivitis, and periodontitis, and more accurately identified an association between HRT and periodontal disease progression by adjusting for other variables such as age, age of menopause, and oral care.

Greendale et al. $^{24)}$, Savolainen-Peltonen et al. ${ }^{25)}$, and Boardman et al. ${ }^{26)}$ stated that both age and menopausal period impacted the effect of HRT. In this study, HRT was more effective in older women. When dividing the subjects into older and middle-aged groups and analyzing the effect of hormone therapy, Rabijewski et al. ${ }^{27)}$ found that bone density increased significantly in the older group whose bone density was low, and it was maintained in the middle-aged group whose bone density was high. Marjoribanks et al. ${ }^{28)}$ reported that estrogen was more effective in those with a longer postmenopausal period and lower bone mass. In this context, according to the prospective studies of Richa et al. ${ }^{29)}$ and Yoshimura et al. ${ }^{30)}$ on postmenopausal women, hormone therapy administered to older women with lower bone density was most effective in terms of changes in bone density, whereas it had no effect in women with normal bone density. These results indicate that the effect of therapy is better because older women have lower bone density than younger women; this is consistent with a 3-year prospective study by PEPI, which reported that contributors to increased bone density after hormone therapy were the patient's age, bone density before therapy, and past hormone therapy administration.

The present study found that HRT's effect was more pronounced when the subjects did not have a dental visit in the past 1 year, did not use oral care products, or brushed their teeth less than 3 times per day. This is related to the finding that HRT is more effective in those with a worse periodontal status. Furthermore, previous studies reported that women who had early menopause had a higher risk of osteoporosis and cardiovascular diseases and a higher mortality rate associated with these diseases than those who had menopause at a normal age ${ }^{31-33)}$. The present study showed that the effect of HRT was more pronounced in those with early menopause, whose age of menopause was less than 45 years, which supports previous findings. To summarize the above findings, those with early menopause had a longer estrogen deficiency period and were more likely to have osteoporosis or bone loss earlier, and therefore, HRT should be considered more actively in these women. In addition, HRT would be more effective when administered to women with early menopause and poor periodontal status.

This study used the KNHANES, which objectively measured periodontal status based on the WHO standard, and attempted to conduct a representative study. Nonetheless, this study has limitations in that it could not identify a causality between the influential variables and the occurrence of periodontal disease because it was a crosssectional study, and it did not consider the HRT period. However, this study is meaningful in that it considered and analyzed various variables that affect HRT and periodontal disease.

\section{References}

1. WHO Scientific Group on Research on the Menopause in the 1990s: Research on the menopause in the 1990s: report of a WHO scientific group. World Health Organization, Geneva, pp.7-31, 1994.

2. Korean Statistical Information Service: A life table in 2015. Retrieved October 3, 2017, from http://kosis.kr/statHtml/ statHtml.do?orgId=101\&tblId=DT_1B42\&vw_cd=\&list_id $=\mathrm{A} 5 \&$ seqNo=\&lang_mode $=$ ko\&language $=$ kor\&obj_var_id $=\& i t m \_i d=\&$ conn_path=MT_ZTITLE (2016, December 2).

3. Lim KY: The study of menopause-related quality of life and management of climacteric in a middle-aged female population in Korea. Public Health Wkly Rep 6: 609-613, 2013. 
4. Korean Statistical Information Service: Population and housing census 2015. Retrieved October 11, 2017, from http://kostat.go.kr/portal/korea/kor_nw/2/1/index.board?bmo $\mathrm{de}=$ read\&aSeq $=360052(2017$, April 19).

5. Oh HJ: Perspectives for managing menopause: general introduction. J Korean Med Assoc 49: 4-10, 2006. https://doi.org/10.5124/jkma.2006.49.1.4

6. G K P, Arounassalame B: The quality of life during and after menopause among rural women. J Clin Diagn Res 7: 135139, 2013. https://doi.org/10.7860/JCDR/2012/4910.2688

7. Shu L, Guan SM, Fu SM, Guo T, Cao M, Ding Y: Estrogen modulates cytokine expression in human periodontal ligament cells. J Dent Res 87: 142-147, 2008. https://doi.org/10.1177/154405910808700214

8. Suri V, Suri V: Menopause and oral health. J Midlife Health 5: 115-120, 2014. https://doi.org/10.4103/0976-7800.141187

9. Park HS, Hwang SJ, Cho MJ, Kim DK, Yang SY: Influence of menstrual cycle on inflammatory markers in gingival crevicular fluid : pilot study. J Dent Hyg Sci 12: 71-77, 2012.

10. Jafri Z, Bhardwaj A, Sawai M, Sultan N: Influence of female sex hormones on periodontium: a case series. J Nat Sci Biol Med 6(Suppl 1): S146-S149, 2015. https://doi.org/10.4103/0976-9668.166124

11. de Villiers TJ, Gass ML, Haines CJ, et al.: Global consensus statement on menopausal hormone therapy. Climacteric 16: 203-204, 2013.

https://doi.org/10.3109/13697137.2013.771520

12. Tarkkila L, Kari K, Furuholm J, Tiitinen A, Meurman JH: Periodontal disease-associated micro-organisms in peri-menopausal and post-menopausal women using or not using hormone replacement therapy. A two-year follow-up study. BMC Oral Health 10: 10, 2010. https://doi.org/10.1186/1472-6831-10-10

13. Haas AN, Rösing CK, Oppermann RV, Albandar JM, Susin C: Association among menopause, hormone replacement therapy, and periodontal attachment loss in southern Brazilian women. J Periodontol 80: 1380-1387, 2009. https://doi.org/10.1902/jop.2009.090082

14. Silveira JL, Albers M, Vargas DM, et al.: Reduced bone stiffness in women is associated with clinical attachment and tooth loss: the study of health in Pomerania. J Dent Res 95: 1464-1471, 2016. https://doi.org/10.1177/0022034516666491
15. Guo Y, Sun N, Duan X, et al.: Estrogen deficiency leads to further bone loss in the mandible of CKD mice. PLoS One 11: e0148804, 2016. https://doi.org/10.1371/journal.pone.0148804

16. Pizzo G, Guiglia R, Licata ME, Pizzo I, Davis JM, Giuliana G: Effect of hormone replacement therapy (HRT) on periodontal status of postmenopausal women. Med Sci Monit 17: PH23-PH27, 2011. https://doi.org/10.12659/MSM.881700

17. Alves RC, Félix SA, Rodriguez-Archilla A, Oliveira P, Brito J, Dos Santos JM: Relationship between menopause and periodontal disease: a cross-sectional study in a Portuguese population. Int J Clin Exp Med 8: 11412-11419, 2015.

18. Yu HJ, Oh JY, Kang JW, et al.: Relationship between menopause, anxiety symptoms and perceived oral symptoms in menopausal women. J Dent Hyg Sci 13: 53-61, 2013.

19. Lee SH, Roh SC: Vitamin D level in blood of menopausal women over 50 and the relation with the proportion requiring dental scaling. J Dent Hyg Sci 13: 393-402, 2013.

20. Rossouw JE, Manson JE, Kaunitz AM, Anderson GL: Lessons learned from the Women's health initiative trials of menopausal hormone therapy. Obstet Gynecol 121: 172-176, 2013. https://doi.org/10.1097/AOG.0b013e31827a08c8

21. Zhao H, Li C, Lin L, et al.: Assessment of alveolar bone status in middle aged Chinese (40-59 years) with chronic periodontitis--using CBCT. PLoS One 10: e0139553, 2015. https://doi.org/10.1371/journal.pone.0139553

22. López-Marcos JF, García-Valle S, García-Iglesias AA: Periodontal aspects in menopausal women undergoing hormone replacement therapy. Med Oral Patol Oral Cir Bucal 10: 132-141, 2005.

23. Singh A, Sharma RK, Siwach RC, Tewari S, Narula SC: Association of bone mineral density with periodontal status in postmenopausal women. J Investig Clin Dent 5: 275-282, 2014. https://doi.org/10.1111/jicd.12047

24. Greendale GA, Espeland M, Slone S, Marcus R, BarrettConnor E; PEPI Safety Follow-Up Study (PSFS) Investigators: Bone mass response to discontinuation of long-term hormone replacement therapy: results from the Postmenopausal Estrogen/Progestin Interventions (PEPI) safety follow-up study. Arch Intern Med 162: 665-672, 2002. https://doi.org/10.1001/archinte.162.6.665

25. Savolainen-Peltonen H, Tuomikoski P, Korhonen $\mathrm{P}$, et al.: 
Cardiac death risk in relation to the age at initiation or the progestin component of hormone therapies. J Clin Endocrinol Metab 101: 2794-2801, 2016.

https://doi.org/10.1210/jc.2015-4149

26. Boardman HMP, Hartley L, Eisinga A, et al.: Hormone therapy for preventing cardiovascular disease in post-menopausal women. Cochrane Database Syst Rev (3): CD002229, 2015. https://doi.org/10.1002/14651858.CD002229.pub4

27. Rabijewski M, Papierska L, Piątkiewicz P: An association between bone mineral density and anabolic hormones in middle-aged and elderly men with prediabetes. Aging Male 20: 205-213, 2017. https://doi.org/10.1080/13685538.2017.1338254

28. Marjoribanks J, Farquhar C, Roberts H, Lethaby A, Lee J: Long-term hormone therapy for perimenopausal and postmenopausal women long-term hormone therapy for perimenopausal and postmenopausal women. Cochrane Database Syst Rev 1: CD004143, 2017. https://doi.org/10.1002/14651858.CD004143.pub5

29. Richa RY, Puranik MP, Shrivastava A: Association between osteoporosis and periodontal disease among postmenopausal
Indian women. J Investig Clin Dent 8: 2017.

https://doi.org/10.1111/jicd.12223

30. Yoshimura N, Kasamatsu T, Sakata K, Hashimoto T, Cooper C: The relationship between endogenous estrogen, sex hormone-binding globulin, and bone loss in female residents of a rural Japanese community: the Taiji Study. J Bone Miner Metab 20: 303-310, 2002.

https://doi.org/10.1007/s007740200044

31. Gambacciani M, Levancini M: Featured editorial hormone replacement therapy and the prevention of postmenopausal osteoporosis. Menopaus Rev 4: 213-220, 2014. https://doi.org/10.5114/pm.2014.44996

32. Joakimsen O, Bonaa KH, Stensland-Bugge E, Jacobsen BK: Population-based study of age at menopause and ultrasound assessed carotid atherosclerosis: the Tromso study. J Clin Epidemiol 53: 525-530, 2000. https://doi.org/10.1016/S0895-4356(99)00197-3

33. Sullivan SD, Sarrel PM, Nelson LM: Hormone replacement therapy in young women with primary ovarian insufficiency and early menopause. Fertil Steril 106: 1588-1599, 2016. https://doi.org/10.1016/j.fertnstert.2016.09.046 